\title{
Effects of Social and Organizational Support on the Satisfaction of International Students and Career Commitment
}

\author{
Sang-Woo Hahm ${ }^{1}$ \\ ${ }^{1}$ Business Administration, Semyung Univ., JECHEON, Republic of Korea thehahm@ @emyung.ac.kr ${ }^{1}$
}

Article History: Received: 11 January 2021; Accepted: 27 February 2021; Published online: 5 April 2021

\begin{abstract}
Perceived organizational support and perceived social support affect individual performance. Their influence may or may not be the same depending on the situation. This study describes the different effects of perceived organizational support and perceived social support on organizational satisfaction and social life satisfaction. Furthermore, it proves that perceived organizational support and perceived social support enhance the organizational (school) satisfaction and social life (life of studying abroad) satisfaction of international students. On addition, through this process, they also increase the career commitment of students. This paper identifies the importance of perceived organizational support and perceived social support necessary to improve the international students' performance, and explain the impact and relevance of their different satisfactions. Through this, this article proposes ways to improve the performance of international students and the discriminatory relevance of perceptions of different objects.
\end{abstract}

Keywords: Perceived organizational support, perceived social support, career commitment, satisfaction

\section{Introduction}

Perceived support means that the organization or society in which individuals belongs is supporting themselves $[1,2]$. An individual can be a member of a particular society, and at the same time belong to a specific organization. Individuals can recognize both organizational and social support at the same time. Organizational support and social support can have a positive impact on individual performance. The impact of organizational and social support on the performance may or may not be the same. This study explains the differential impact of organizational and social support on satisfaction, which is the performance-related variable of the members.

The subjects of this study are international students, who perceive the organization's support and the impact of social support while in the country. The performance-related variables of international students were set to satisfaction with school and satisfaction with studying abroad. Furthermore, this stud proves that students who are satisfied with school and studying abroad can be more committed to their career after returning home. This paper will emphasize the importance of perceived support for improving the satisfaction of students studying abroad. Furthermore, for the successful study abroad experience, this study proposes different roles between school and life satisfaction to improve the career commitment. In addition, this research emphasizes the importance of satisfaction with studying abroad and schools for a successful study abroad life that will enhance the career commitment of international students in a global context. The effects of perceived support will be explained as a way to improve them. The purpose of this study is to explain the influence of factors necessary for the successful study abroad experience of students and to explain the differentiating influence of different objects (organization and society) on different effects (school and life).

\section{Literature review}

\section{Perceived support}

Perceived organizational support (POS) can be explained by the organization's interest in member contributions and welfare. First, POS recognizes that the organization considers the degree to which the members themselves contribute to the organization. Second, this refers to the workers' perceptions of the extent to which the organization cares and supports the welfare [1,3]. POS is an individual perception of the degree to which an organization is immersed in workers [4]. Members have a positive attitude toward the organization when they recognize organization is committed to supporting their well-being. Perceived social support (PSS) is the degree to which the support, feedback and information that an individual wants is received by friends and family [5]. PSS in schools arises from family, peers, and teachers, and has a positive effect on student interest, motivation, school adaptation, academic performance, capability, and achievement [6].

\section{Satisfaction}

Traditionally, satisfaction with the organization can be described as the individual's comprehensive satisfaction with the organization itself, organizational structure and policies [7]. For example, workers can be satisfied with their workplace since it can be said that a positive emotional state arise from the evaluation of the workplace $[8,9]$. Organizational satisfaction is a member's personal attitude towards the work environment and the organization as a whole $[10,28]$. Therefore, school satisfaction (SS) can be said to be the students' positive attitudes or feelings toward school. This SS is a specific positive attitude towards the school and the educational experiences [11]. 
Life satisfaction is a comprehensive evaluation of a person's quality of life according to specific criteria, and consists of cognitive judgmental processes about life [12]. Life satisfaction is personal evaluation about one's environment. An individual who perceives satisfaction with life considers life closer to one's own ideals. These individuals are satisfied with their lives and think there is nothing to change, and they think their living conditions are good. In addition, these people perceive that they have gotten important things they want in life [13]. Therefore, satisfaction with the life of studying abroad (SLSA) is a comprehensive evaluation of one's studying abroad experience, and it can be seen to the extent that international students meet their own ideology, are satisfied with their lives, and get important things while living abroad.

\section{Perceived support and satisfaction}

POS has a positive role in improving performance such as satisfaction and commitment [14]. When the POS is high, the social and emotional needs of the members are satisfied. They consider themselves to be properly evaluated and recognized. In this case, the members think that the profit or loss of the organization is their own profit or loss. This internalization makes people more satisfied and committed in the organization [1]. On the other hand, when the POS is low, the members have the fear that the organization will exploit them. Thus, they will reduce efforts to improve business performance [3]. POS encourages members to increase their interest and loyalty as well as have a positive attitude toward the organization [15]. Hence, POS will inspire positive attitudes toward organizations such as schools and society. In this regard, the hypotheses about the effects of POS on SS and SLSA were established as follows:

\section{H1. POS will have a positive effect on SS. \\ H2. POS will have a positive impact on SLSA.}

Similar to POS, life satisfaction is closely related to satisfaction with organizations in their life. People who are socially recognized and supported are more likely to have a more positive attitude towards their society and organization. PSS will be more recognizable to members when social networking, such as smooth communication, operates positively. A positive attitude towards social networking can improve one's life satisfaction [12]. When an individual is satisfied with oneself, this person will be more satisfied with the organization one belongs to. Based on this relevance, the following hypotheses were established:

\section{H3. PSS will have a positive impact on SS.}

H4. PSS will have a positive impact on SLSA.

\section{Career commitment}

People feel committed to personal purpose for individual career development. Career commitment (CC) specifically means the people's motivation to work hard to achieve their careers. CC begins with the idea that people see careers as one of the most important elements in life. Workers with CC are contemplating what they can achieve in their jobs, and are successful and proud of their careers [16]. CC refers to a specific attitude towards the individual profession, job, or vocation [17]. A person with a high CC represents a high level of motivation and expectations in one's organization. They also are more satisfied, and motivated to work and have a higher commitment to organizations [18].

The effects of perceived support on CC through satisfaction

Members with a high level of POS become more satisfied with their organizations [19], and this attitude of satisfaction increases the behavior of commitment [20]. Members who are satisfied with a particular organization are more motivated and tend to continue developing themselves. These members regard their organization as a structure that can meet social and psychological needs and, not simply a means of making money [21, 22]. More satisfied members act for more goals and more actively participate in organizational activities than those who feel less satisfied [23]. This process will result in more commitment to their career due to satisfaction. Based on this relevance, the following hypotheses were established:

H5. SS will mediate the relationship between POS and CC.

H6. SLSA will mediate the relationship between POS and CC.

H7. SS will mediate the relationship between PSS and CC.

H8. SLSA will mediate the relationship between PSS and CC.

\section{Measurement and Participants}

All items in this study were measured on a Likert 7-point scale. First, POS was measured by 4 items such as "This school would not ignore complaints from me" and "My school really cares about my well-being" [4]. Second, PSS was measured by 8 items, including, "Tell you that they appreciate your efforts", "Encourage you to do well" [6]. SS was measured by 6 items, involves "I enjoy being a student on this campus", "I feel comfortable at this 
university" [11]. SLSA was measure by 4 items, including "I am satisfied with my life", "In most ways my life is close to my ideal" [12]. CC was measured by 6 items such as "The ambitions in my life mainly have to do with my career", "I think that I should have a successful career" [16].

Data was collected from 164 Chinese international students studying in Korea. In terms of gender, there were 58 males (35.4\%) and 106 females (64.6\%). In terms of age, 43 were 18-20 (26.2\%), 112 were 21-24 (68.3\%), and 9 were older than $25(5.5 \%)$. In regards to their length of employment, 14 had worked for less than 1 year $(7.3 \%), 62$ had worked 1-5 years $(32.5 \%), 59$ had worked 5-10 years (30.9\%), and 56. In regards to their length of study, 60 had studied for less than 1 year(36.5\%), 74 had studied $1-2$ years $(45.1 \%)$ and 30 had studied more 2 years(18.4\%)

I.

Analysis

Results of the exploratory factor analysis(EFA) with vari-max rotation, confirmatory factor analysis(CFA), and reliability are present in table (1). Each variable has a significant validity and sufficient reliability.

Table 1 Results of EFA, CFA and reliability

\begin{tabular}{|c|c|c|c|c|c|c|}
\hline \multirow{2}{*}{$\begin{array}{c}\mathrm{Cr} \\
\text { onbac } \\
\text { h' }\end{array}$} & & \multicolumn{5}{|c|}{ Component $\mathrm{KMO}=.938(\mathrm{sig}=.000)$} \\
\hline & & 1 & 2 & 3 & 4 & 5 \\
\hline \multirow{6}{*}{$74^{.9}$} & SS1 & .2 & .7 & .3 & .1 & .2 \\
\hline & SS2 & .2 & .8 & .3 & .1 & .1 \\
\hline & SS3 & .2 & .8 & .3 & .1 & .2 \\
\hline & SS4 & .2 & .7 & .2 & .2 & .3 \\
\hline & SS5 & .2 & .8 & .2 & .2 & .2 \\
\hline & SS6 & .1 & .8 & .2 & .2 & .2 \\
\hline \multirow{4}{*}{$59^{.9}$} & POS & .3 & .2 & .2 & .8 & .1 \\
\hline & POS & .3 & .2 & .1 & .8 & .1 \\
\hline & POS & .3 & .2 & .2 & .8 & .1 \\
\hline & POS & .3 & .1 & .2 & .7 & .2 \\
\hline \multirow{8}{*}{$73^{.9}$} & PSS & .8 & .0 & .2 & .1 & .1 \\
\hline & PSS & .8 & .1 & .2 & .2 & .0 \\
\hline & PSS & .8 & .1 & .1 & .2 & .0 \\
\hline & PSS & .8 & .1 & .1 & .2 & .1 \\
\hline & PSS & .8 & .2 & .1 & .1 & .2 \\
\hline & PSS & .8 & .2 & .2 & .1 & .2 \\
\hline & PSS & .8 & .2 & .1 & .1 & .1 \\
\hline & PSS & .7 & .2 & .2 & .2 & .2 \\
\hline \multirow{6}{*}{$53^{.9}$} & $\mathrm{CC} 1$ & .2 & .3 & .7 & .1 & .2 \\
\hline & $\mathrm{CC} 2$ & .2 & .2 & .7 & .2 & .3 \\
\hline & CC3 & .2 & .2 & .7 & .1 & .1 \\
\hline & $\mathrm{CC} 4$ & .2 & .2 & .8 & .1 & .0 \\
\hline & $\mathrm{CC5}$ & .2 & .2 & .7 & .1 & .1 \\
\hline & CC6 & .3 & .2 & .7 & .1 & .1 \\
\hline \multirow{4}{*}{$34^{9}$} & SLS & .2 & .2 & .2 & .1 & .7 \\
\hline & SLS & .1 & .3 & .2 & .1 & .8 \\
\hline & SLS & .1 & .2 & .2 & .1 & .7 \\
\hline & SLS & .3 & .3 & .3 & .1 & .6 \\
\hline \multicolumn{2}{|c|}{ Total } & 6. & 5. & 4. & 3. & 3. \\
\hline \multicolumn{2}{|c|}{$\%$ of } & 24 & 19 & 17 & 12 & 12 \\
\hline \multicolumn{2}{|c|}{ Cumulative } & 24 & 43 & 61 & 73 & 85 \\
\hline
\end{tabular}


$X^{2}(\mathrm{p})=562.092, X^{2} / \mathrm{df}=1.762, \mathrm{RMSEA}=.068, \mathrm{TLI}=.954$,

CFI $=.961, \mathrm{IFI}=.962, \mathrm{PNFI}=.773, \mathrm{PGFI}=.641$

Table (2) shows correlations among variables. All variables have significant relationship.

Table 2. Results of Correlations

\begin{tabular}{|r|c|c|c|c|c|}
\hline & POS & PSS & SS & SLSA & CC \\
\hline POS & - & & & & \\
\hline PSS & $.658^{*}$ & - & & & \\
SS & $.593^{*}$ & $.561^{*}$ & - & & \\
\hline SLS & $.583^{*}$ & $.553^{*}$ & $.685^{*}$ & - & \\
\hline CC & $.569^{*}$ & $.597^{*}$ & $.680^{*}$ & $.632^{*}$ & - \\
\hline
\end{tabular}

Figure (1) indicates the relevance of variables by structural equation model. The fit index of this model is as follows. $\mathrm{X} 2(\mathrm{p})=673.670, X^{2} / \mathrm{df}=2.112, \mathrm{TLI}=.933, \mathrm{CFI}=.944, \mathrm{IFI}=.944, \mathrm{PNFI}=.759, \mathrm{PGFI}=.623$. As a result, it has been shown that POS has significant effects on SS(.44) and SLSA(.37). Hence, hypotheses 1 and 2 were supported Also, PSS has significant effects on SS (.23), and SLSA (.18). Thus, hypotheses, 3 and 4 were also supported.

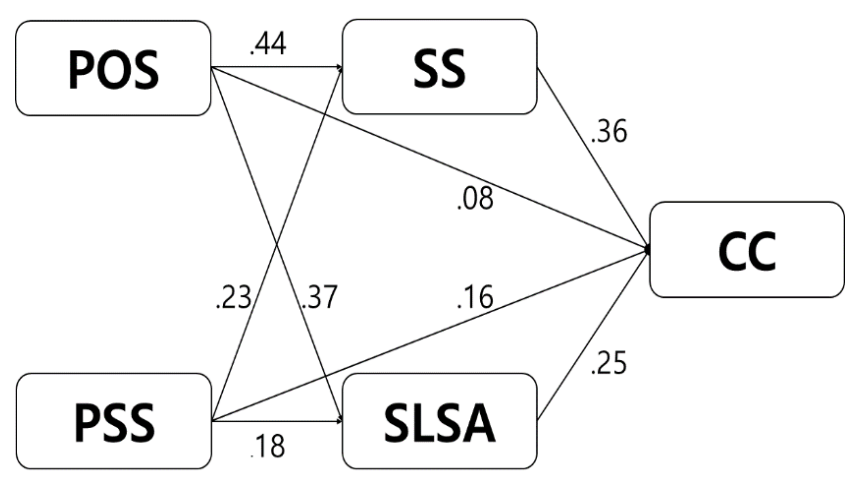

Figure 1. Result of structural equation model

In addition, the mediation effect was verified through regression analysis and Sobel test. Table (3) indicates results of mediating effect of SS, and Table (4) showed mediating effect of SLSA. In Table (3), effect of POS was decreased $(\beta=.569$ to $\beta=.255)$, and SS has significant effect $(\beta=.530)$. Also, in Table (4), effect of POS was decreased ( $\beta=.569$ to $\beta=.303)$, and SS has significant effect $(\beta=.456)$. These results mean that in the relationship between POS and CC, both SS and SLSA have a partial mediating effect. The Sobel test results also showed a significant mediating effect. Therefore, hypotheses 5 and 6 were adopted.

Table 3. Mediating effects of SS between POS and CC

\begin{tabular}{|c|r|r|r|r|r|r|}
\hline \multirow{2}{*}{} & \multicolumn{3}{|c|}{ step 1 } & \multicolumn{3}{|c|}{ step 2 } \\
\cline { 2 - 7 } & $\beta$ & $t$ & $\mathrm{~s}$ & $\beta$ & $t$ & $\mathrm{~s}$ \\
\hline POS & .5 & 8. &. &. & 3. &. \\
\hline $\mathrm{SS}$ & & & &. & 7. &. \\
\hline$R^{2}\left(\right.$ Adj- $\left.R^{2}\right)$ & \multicolumn{2}{|c|}{$.323(.319)$} & \multicolumn{2}{|c|}{$.505(.499)$} \\
\hline$\Delta \mathrm{R}^{2}(\mathrm{Adj}-$ & \multicolumn{3}{|c|}{-} & \multicolumn{2}{|c|}{$.182(.180)$} \\
\hline$F$ & \multicolumn{2}{|c|}{$77.364(\mathrm{sig}=.000$} & \multicolumn{2}{|c|}{$82.138(\mathrm{sig}=.00$} \\
\hline \multicolumn{3}{|c|}{ Sobel test } & \multicolumn{2}{|c|}{$7.305(p<.001)$} \\
\hline
\end{tabular}


Table 4. Mediating effects of SLSA between POS and CC

\begin{tabular}{|c|r|r|r|r|r|r|}
\hline & \multicolumn{3}{|c|}{ step 1 } & \multicolumn{3}{c|}{ step 2 } \\
\cline { 2 - 6 } & $\beta$ & $t$ & $\mathrm{~s}$ & $\beta$ & $t$ & $\mathrm{~s}$ \\
\hline POS & .5 & 8. &. &. & 4. &. \\
\hline SLSA & & & &. & 6. &. \\
\hline$R^{2}\left(\right.$ Adj- $\left.R^{2}\right)$ & \multicolumn{2}{|c|}{$.323(.319)$} & \multicolumn{2}{|c|}{$.460(.454)$} \\
\hline$\Delta \mathrm{R}^{2}($ Adj- & \multicolumn{3}{|c|}{-} & \multicolumn{2}{|c|}{$.137(.135)$} \\
\hline$F$ & $77.364(\mathrm{sig}=.000$ & \multicolumn{2}{|c|}{$68.644(\mathrm{sig}=.00$} \\
\hline
\end{tabular}

Table (5) and (6) display the results of mediating effect of SS and SLSA between PSS and CC. As a result, the influence of PSS on CC decreased from $\beta=.597$ to $\beta=.314(\mathrm{SS})$ and $\beta=.356$ (SLSA). Also, it was found that $\operatorname{SS}(\beta=.504)$ and $\operatorname{SLSA}(\beta=.435)$ had a significant effect on CC. Moreover, the results of Sobel test showed significant mediating effects of SS and SLSA. Based on these results, hypotheses 7 and 8 were adopted.

Table 5. Mediating effect of SSbetween PSS and CC

\begin{tabular}{|c|c|c|c|c|c|c|}
\hline & \multicolumn{3}{|c|}{ step 1} & \multicolumn{3}{|c|}{ step 2} \\
\hline & $\beta$ & $t$ & $\mathrm{~s}$ & $\beta$ & $t$ & $\mathrm{~s}$ \\
\hline PSS & .5 & 9. & . & . & 4. & . \\
\hline SLSA & & & & . & 7. & . \\
\hline$R^{2}\left(\operatorname{Adj}-R^{2}\right)$ & \multicolumn{3}{|c|}{$.356(.352)$} & \multicolumn{3}{|c|}{$.531(.525)$} \\
\hline$\Delta \mathrm{R}^{2}(\operatorname{Adj}-$ & \multicolumn{3}{|c|}{-} & \multicolumn{3}{|c|}{$.175(.173)$} \\
\hline$F$ & \multicolumn{3}{|c|}{89.664} & \multicolumn{3}{|c|}{$90.995(\mathrm{sig}=.00$} \\
\hline \multicolumn{4}{|c|}{ Sobel test } & \multicolumn{3}{|c|}{$6.939(p<.001)$} \\
\hline
\end{tabular}

Table 6. Mediating effect of SLSA between PSS and CC

\begin{tabular}{|c|r|r|r|r|r|r|}
\hline & \multicolumn{3}{|c|}{ step 1 } & \multicolumn{3}{c|}{ step 2 } \\
\cline { 2 - 7 } & $\beta$ & $t$ & $\mathrm{~s}$ & $\beta$ & $t$ & $\mathrm{~s}$ \\
\hline PSS & .5 & 9. &. &. & 5. &. \\
\hline SLSA & & & &. & 6. &. \\
\hline$R^{2}\left(\mathrm{Adj}-R^{2}\right)$ & \multicolumn{2}{|c|}{$.356(.352)$} & \multicolumn{3}{|c|}{$.488(.481)$} \\
\hline$\Delta \mathrm{R}^{2}(\mathrm{Adj}-$ & \multicolumn{3}{|c|}{-} & \multicolumn{2}{|c|}{$.132(.129)$} \\
\hline$F$ & \multicolumn{3}{|c|}{89.664} & \multicolumn{2}{|c|}{76.628} \\
\hline
\end{tabular}

\section{Conclusion}

Results and implications

SS represents the organization such as the university. It has been shown that POS (.44), which is related to the organization, has more influence on SS than PSS (.23), which is related to society. However, despite the fact that SLSA is not about the attitude toward the organization, but about studying abroad, it has been shown that the influence of POS (.23) is greater than that of PSS (.18). This means that the support of the school(organization) is more important than ever for the SS and SLSA of international students. In addition, the SS (.36) was found to have more influence on CC than SLSA(.25). The influence of POS (.08) and PSS (.16) was also relatively low. These results mean that students who are satisfied with school can be more confident and committed to their future careers $[24,25]$. Furthermore, through the mediating effect, it can be seen that the process of improving CC by raising SS through POS is the most effective.

These findings explain what elements are needed to improve the performance of international students in a global environment from a practical point of view. Since, POS can improve the SS and SLSA of international students, schools should try to actively support them [26]. In addition, knowing that school satisfaction is an essential element for the success of studying abroad, the university has to find ways to increase school satisfaction 
[27]. In the academic domain, these results explain whether the concepts of organization and social support have a discriminatory impact on schools (organizations) and life (societies). The differential impact of school and life satisfaction on career commitment has also been demonstrated. Hence, similar attempts will be made in future research by finding different influences of the variables that deal with these different objects.

\section{Limitations and suggestions for future research}

First, in this study, CC was measured at the same time as other variables. In the future, it will be necessary to look at how successful students are in their careers after returning to theirhome country. Second, this study described the process of perceived support affecting satisfaction and CC. This is the result of not considering various situational factors. Future research will also require the verification of the moderating effects of diverse variables such as the students' values and personalities. Third, if the SS and SLSA are improved, more detailed studies need to be conducted to see if other variables such as grades are affected as well as CC. Finally, this study was conducted on Chinese students studying abroad in Korea. These participants will be influenced by their own cultures. Therefore, future studies should have students from more diverse cultures.

\section{References}

1. Eisenberger, R., Huntington, R., Hutchison, S.,\& Sowa, D.(1986). Perceived organizational support, Journal of Applied Psychology, 71(3), pp.500-507.

2. Hahm, S. W.(2016). To enhance work engagement of informational technology workers: effect of commitment to the growth of people, perceived organizational support and expectancy. The Journal of the Institute of Internet, Broadcasting and Communication, 16(6), 265-275.

3. Eisenberger, R., Fasolo, P.,\& Davis-LaMastro, V.(1990). Perceived organizational support and employee diligence, commitment, and innovation.Journal of Applied Psychology, 75(1), pp.51-59.

4. Johlke, M. C., Stamper, C. L., \& Shoemaker, M. E. (2002). Antecedents to boundary-spanner perceived organizational support. Journal of Managerial Psychology, 17(2), 116-128.

5. Procidano, M. E., \& Heller, K.(1983). Measures of perceived social support from friends and from family: Three validation studies. American Journal of Community Psychology, 11(1), 1-24.

6. Rosenfeld, L. B., \& Richman, J. M.(1999). Supportive communication and school outcomes, Part II: Academically "at-risk" low income high school students. Communication Education, 48(4), 294-307.

7. Warr, P. B.,\& Routledge, T.(1969). An opinion scale for the study of manager's job satisfaction.Occupational Psychology, 43, pp.95-109.

8. Gazzoli, G., Hancer, M.,\& Park, Y.(2010). The Role and effect of job satisfaction and empowerment on customer's perception of service quality: A study in the restaurant industry.Journal of Hospitality \& Tourism, 34(1), pp.56-77.

9. Locke, E. A.(1975). Personal Attitude and Motivation.Annual Review of Psychology, 26, pp.457480.

10. Army, R. N.(2004). Determining the Influences on Motivation, Commitment, Satisfaction, Absenteeism and Turnover with a New Questionnaire: PICTURE.

11. Butler, A. B.(2007). Job characteristics and college performance and attitudes: A model of workschool conflict and facilitation. Journal of Applied Psychology, 92(2), 500-510.

12. Oh, H. J., Ozkaya, E., \& LaRose, R.(2014). How does online social networking enhance life satisfaction? The relationships among online supportive interaction, affect, perceived social support, sense of community, and life satisfaction. Computers in Human Behavior, 30, 69-78.

13. Diener, E., Emmons, R. A., Larsen, R. J., \& Griffin, S.(1985). The satisfaction with life scale. Journal of Personality Assessment, 49, 71-75.

14. Malik, M. E., Nawab, S., Naeem, B., \& Danish, R. Q. (2010). Job satisfaction and organizational commitment of university teachers in public sector of Pakistan. International Journal of Business and Management, 5(6), 17-26.

15. Krishnan, J., \& Mary, V. S.(2012). Perceived organisational support-an overview on its antecedents and consequences. International Journal of Multidisciplinary Research, 2(4), 2-13.

16. Ellemers, N., de Gilder, D., \& Van Den Heuvel, H. (1998). Career-oriented versus team-oriented commitment and behavior at work. Journal of Applied Psychology, 83(5), 717-730.

17. Blau, G. J.(1985). The measurement and prediction of career commitment. Journal of Occupational Psychology, 58(4), 277-288.

18. Chang, E.(1999). Career commitment as a complex moderator of organizational commitment and turnover intention. Human Relations, 52(10), 1257-1278.

19. Ayim Gyekye, S. (2005). Workers' perceptions of workplace safety and job satisfaction. International Journal of Occupational Safety and Ergonomics, 11(3), 291-302. 
20. Ariani, D. W.(2012). Leader-member exchanges as a mediator of the effect of job satisfaction on affective organizational commitment: An empirical test. International Journal of Management, 29(1), 46-56.

21. Laguador, J. M., De Castro, E. A., \& Portugal, L. M. (2014). Employees' Organizational Satisfaction and Its Relationship with Customer Satisfaction Measurement of an Asian Academic Institution. Quarterly Journal of Business Studies, 1(3), 83-93.

22. Şahin, İ., Akyürek, C. E., \& Yavuz, Ş.(2014). Assessment of effect of leadership behaviour perceptions and organizational commitment of hospital employees on job satisfaction with structural equation modelling. Journal of Health Management, 16(2), 161-182.

23. Aryee, S., Budhwar, P. S., \& Chen, Z. X.(2002). Trust as a mediator of the relationship between organizational justice and work outcomes: Test of a social exchange model. Journal of Organizational Behavior: The International Journal of Industrial, Occupational and Organizational Psychology and Behavior, 23(3), 267-285.

24. Cheng, W., \& Hahm, S. (2017). Cultural Approach for Future Plan Orientation: Chinese Students Study Abroad. International Journal of Advanced Culture Technology, 5(4), 38-43.

25. Hahm, S.(2017), The Effect of the Attitude to Labor Unions and Union-Management Cooperation on Organizational Commitment and Organizational Citizenship Behavior: Evidence from the IT Industry.The Journal of The Institute of Internet, Broadcasting and Communication,17(1), pp.269279.

26. Hahm, S., \& Sun, S.(2020). The Effect of Professor's Individualized Consideration on the Personal Growth of Chinese Students Study Abroad in Korea: The Moderating Effect of Perceived School Support. International Journal of Advanced Culture Technology, 8(2), 76-84.

27. Zheng, F., \& Hahm, S.(2019). The Effects of Professors' Transformational Leadership on the Improvement of Chinese Students' University Satisfaction: The Mediating Effects of University Identification. International Journal of Advanced Culture Technology, 7(4), 137-144.

28. Galatti, L. R., Marques, R. F., Barros, C. E., Montero Seoane, A., \& Rodrigues Paes, R. (2019). Excellence in Women Basketball: Sport Career Development of World Champions and Olympic Medalists Brazilian Athletes. Revista de psicología del deporte, 28(3), 0017-23. 